\title{
Contribution of membrane progesterone receptor $\alpha$ to the induction of progesterone-mediated apoptosis associated with mitochondrial membrane disruption and caspase cascade activation in Jurkat cell lines
}

\author{
ASAMI KON ${ }^{1}$, BO YUAN ${ }^{1,2}$, TOMOYUKI HANAZAWA ${ }^{1}$, HIDETOMO KIKUCHI ${ }^{1}$, \\ MARI SATO $^{1}$, RYOTA FURUTANI $^{1}$, NORIO TAKAGI ${ }^{2}$ and HIROO TOYODA ${ }^{1}$ \\ Departments of ${ }^{1}$ Clinical Molecular Genetics, and ${ }^{2}$ Applied Biochemistry, School of Pharmacy, \\ Tokyo University of Pharmacy and Life Sciences, Hachioji, Tokyo 192-0392, Japan
}

Received May 30, 2013; Accepted July 3, 2013

DOI: 10.3892/or.2013.2657

\begin{abstract}
In the present study, we investigated the effects of progesterone $(\mathrm{Pg})$ on the growth of A3 and its caspase-8-deficient mutant cell line, I9.2, both of which are subclones of a T-cell-derived leukemic Jurkat cell line that lacks the classic cytoplasmic/nuclear Pg receptor. Pg inhibited the cell growth of both cell lines in a dose- and time-dependent manner to a similar extent, regardless of the status of caspase- 8 expression. The activation of caspase- 9 and -3 was observed in both cell lines following treatment with $50 \mu \mathrm{M}$ Pg for $24 \mathrm{~h}$. In addition, the activation of caspase- 8 was observed in A3 cells. The addition of the pan-caspase inhibitor Boc-D-FMK, significantly suppressed Pg-triggered cytocidal effects in both types of cells. Moreover, exposure to $50 \mu \mathrm{M}$ Pg for 48 and $72 \mathrm{~h}$ resulted in lactate dehydrogenase leakage characteristic of the disruption of cellular membrane integrity. The function of membrane progesterone receptor $\alpha$ coupled directly with the Gi protein was revealed based on the restoration of Pg-triggered loss of mitochondrial membrane potential in the presence of pertussis toxin, an inhibitor specific for Gi protein. These results suggest that growth suppression accompanied with induction of apoptosis by Pg in both Jurkat clone cells was mediated through mitochondrial membrane disruption followed by the activation of the caspase cascade, as a result of the activation of nongenomic effects. The results of the present study provide novel
\end{abstract}

Correspondence to: Dr Bo Yuan or Professor Hiroo Toyoda, Department of Clinical Molecular Genetics, School of Pharmacy, Tokyo University of Pharmacy and Life Sciences, 1432-1 Horinouchi, Hachioji, Tokyo 192-0392, Japan

E-mail: yuanbo@toyaku.ac.jp

E-mail: toyoda-h@toyaku.ac.jp

Key words: progesterone, Jurkat cells, membrane progesterone receptor coupled with Gi-protein, apoptosis induction, caspase activation, mitochondrial membrane disruption insight into Pg actions toward its use for clinical application in patients with lymphocytic T cell leukemia.

\section{Introduction}

Progesterone $(\mathrm{Pg})$ is known to play a pivotal role in the reproductive cycle and pregnancy, in which the fetal-maternal immune response is suppressed during pregnancy (1). Furthermore, it has been well documented that Pg contributes to the control of T-cell-mediated autoimmune reactions, in which the immune balance between $\mathrm{CD}^{+}{ }^{+} \mathrm{T}$-helper Th1 and Th2 cells is regulated (2). Pg induces apoptosis in Th1 cells, whereas $\mathrm{Pg}$ is metabolized into non-toxic $20 \alpha$-hydroxyprogesterone by $20 \alpha$-hydroxysteroid dehydrogenase for the escape of Th2 cells from apoptosis (3). On the basis of a common theory, it is believed that Pg binds to the classic cytoplasmic/nuclear Pg receptor $(\mathrm{PR})$ in order to modulate gene expression, a process which is known as genomic effects (1). Genomic effects are not restricted to immune-associated cells, but are also well known in various types of cells including tumor cells $(1,4-7)$. Indeed, it has been demonstrated that Pg induces apoptosis in diverse types of tumor cells, such as mesothelioma cells and breast, cervical and ovarian cancer cells by activating the genomic signaling pathway (4-7). Results of the investigation of the antiproliferative action of Pg against tumor cells suggest that Pg acts on non-target cells devoid of classic PR through a different process known as non-genomic effects. In fact, a recent study using a uterine cervix-derived cell line lacking classic PR demonstrated that the arrest of the cell cycle at the G1/G0 phase as well as apoptosis induction was responsible for Pg-mediated dose-dependent growth inhibition (8).

Intensive research for identifying receptor molecules for $\mathrm{Pg}$ to manifest rapid functioning has been conducted. Recently, cell membrane-bound progesterone receptors (mPRs) unrelated to the classic PR, which are composed of $\operatorname{mPR} \alpha, \operatorname{mPR} \beta$ and $m P R \gamma$, have received a great deal of attention (9-14). It is believed that rapid responses to $\mathrm{Pg}$ are initiated by binding to a respective receptor localized on the cell membrane (i.e., mPR) coupled with inhibitory G-proteins (Gi) $(9,12,14)$. 
Indeed, progestin, a synthetic Pg, has been demonstrated to activate a variety of signaling pathways through $\mathrm{mPR} \alpha$ (14). It has been further demonstrated that the binding of $\operatorname{Pg}$ to $\mathrm{mPR} \alpha$ alters secondary messenger pathways through activation of the pertussis toxin (PTX)-sensitive Gi $(2,13,14)$.

As mentioned above, Pg plays a pivotal immunoregulatory role by regulating the balance between Th1 and Th2 cells. Moreover, Gamberucci et al (15) demonstrated that Pg inhibited capacitative $\mathrm{Ca}^{2+}$ entry in Jurkat $\mathrm{T}$ lymphocytes in case of the binding of $\mathrm{Pg}$ to membrane, and proposed an involvement of non-genomic mechanism for the inhibitory effects of Pg. Recently, mPRs including $\mathrm{mPR} \alpha$ and $\mathrm{mPR} \beta$ have been detected in human peripheral blood leukocytes, $\mathrm{T}$ lymphocytes and Jurkat cells, suggesting a potential novel mechanism for the immunoregulatory function of $\mathrm{Pg}$ through activation of mPRs (16). However, the effects of Pg on Jurkat cells have not yet been investigated in detail in regard to antiproliferation as well as apoptosis induction. In the present study, we investigated the effects of Pg on a classic PR-negative Jurkat cell line, A3, and its caspase-8 deficient mutant cell line, I9.2 (17,18). We also used PTX, an inhibitor specific for Gi protein, to clarify the involvement of mPR $\alpha$ in the non-genomic Pg signaling pathway, since $\mathrm{mPR} \alpha$ has been well documented in mediating Pg actions among the mPRs $(14,19,20)$.

\section{Materials and methods}

Cell culture. Human acute lymphocytic T-cell leukemia derived from a lymphoblastoid cell line Jurkat clone A3, which is sensitive to Fas-mediated apoptosis, and I9.2, which is a caspase-8-deficient mutant of A3 $(17,18)$ were obtained from the American Type Culture Collection (ATCC, Manassas, VA, USA). Cells were cultured as previously described (6) in RPMI-1640 medium without Phenol red (Sigma-Aldrich, St. Louis, MO, USA) supplemented with $10 \%$ charcoal stripped fetal bovine serum (FBS) (Biological Industries, Kibbutz Beit Haemek, Israel) and $10 \mathrm{mg} / \mathrm{ml}$ gentamicin (Life Technologies, Carlsbad, CA, USA) at $37^{\circ} \mathrm{C}$ in a humidified atmosphere $\left(5 \% \mathrm{CO}_{2}\right.$ in air). Peripheral blood mononuclear cells (PBMNCs) were isolated from three healthy volunteers using Histopaque-1077 (Sigma) according to the manufacturer's instructions, and cultured in RPMI-1640 medium without Phenol red supplemented with $10 \%$ charcoal stripped FBS, $100 \mathrm{U} / \mathrm{ml}$ penicillin and $100 \mu \mathrm{g} / \mathrm{ml}$ streptomycin (Life Technologies) at $37^{\circ} \mathrm{C}$ in a humidified atmosphere $\left(5 \% \mathrm{CO}_{2}\right.$ in air). For experiments, the cell density was adjusted to $5 \times 10^{5}$ cells $/ \mathrm{ml}$ prior to the treatments. The present study was approved by the IRB Committee of Tokyo University of Pharmacy and Life Sciences. An informed consent was obtained from all healthy volunteers.

Treatment with Pg in the presence or absence of Boc-D-FMK. Cells were seeded on flasks or plates at $1 \times 10^{5}$ cells $/ \mathrm{ml}$, followed by treatment with different concentrations of $\mathrm{Pg}$ for different period of time as indicated. In order to clarify the implication of the caspase cascade in the effects of $\mathrm{Pg}$, cells were preincubated with Boc-D-FMK, a pancaspase inhibitor (Sigma-Aldrich), at the indicated concentrations for $1 \mathrm{~h}$, before the addition of Pg at a final concentration of $50 \mu \mathrm{M}$, followed by an additional incubation for $24 \mathrm{~h}$.
Cell viability assay. After treatment with various concentrations of $\mathrm{Pg}(10-100 \mu \mathrm{M})$ in the presence or absence of Boc-D-FMK for the designated time, cell viability was measured by 2,3-bis(2-methoxy-4-nitro-5-sulfophenyl)-5((Phenyl-amino)-carboxyl)-2H-tetrazolium hydroxide (XTT) assay (Sigma-Aldrich) as previously described (21). Relative cell viability was calculated as the ratios of the absorbance at $450 \mathrm{~nm}$ of each treatment group against the respective control group.

Cell cycle analysis. After treatment with $50 \mu \mathrm{M}$ Pg for 24 and $48 \mathrm{~h}$, cell cycle analysis was performed using a FACSCanto flow cytometer (Becton-Dickinson, Mountain View, CA, USA) according to a method reported previously with modifications (22). For staining cellular DNA, cells were washed twice with PBS, fixed with $1 \%$ paraformaldehyde/PBS for $30 \mathrm{~min}$, and then washed twice again with PBS, permeabilized in $70 \%(\mathrm{v} / \mathrm{v})$ cold ethanol and maintained at $-20^{\circ} \mathrm{C}$ for at least $4 \mathrm{~h}$. Then, cell pellets were washed twice with PBS after centrifugation and incubated with $0.25 \%$ Triton X-100 for 5 min on ice. After centrifugation and washing with PBS, cells were resuspended in $500 \mu \mathrm{l}$ of propidium iodide (PI)/RNase A/PBS $(5 \mu \mathrm{g} / \mathrm{ml}$ PI and $0.1 \%$ RNase A in PBS) and incubated for $30 \mathrm{~min}$ in the dark at room temperature. A total of 10,000 events were acquired and Diva software (Becton-Dickinson) and ModFit LT $^{\mathrm{TM}}$ version 3.0 (Verity Software House, Topsham, ME, USA) were used to calculate the number of cells at each sub-G1, G0/G1, S and G2/M phase fraction.

Lactate dehydrogenase ( $L D H)$ assay. After treatment with $50 \mu \mathrm{M}$ Pg for 48 and $72 \mathrm{~h}$, LDH leakage from cells was measured using the LDH-Cytotoxic Test Wako kit (Wako Pure Chemical Industries, Osaka, Japan) according to the method previously described with slight modifications (23). Briefly, after the cells were centrifuged at $450 \mathrm{xg}$ for $5 \mathrm{~min}$ at $4^{\circ} \mathrm{C}$, $25 \mu \mathrm{l}$ of culture supernatants was collected and transferred into wells of a 96-well plate, followed by the addition of $25 \mu \mathrm{l}$ PBS to each well. After discarding the remaining culture supernatants, the cells were lysed with $200 \mu \mathrm{l}$ of $0.1 \%$ Triton X-100. A portion of cell lysates $(12.5 \mu \mathrm{l})$ was subsequently loaded into the 96-well plate, followed by the addition of $37.5 \mu 1$ to each well. LDH activities in both the culture supernatants and the cell lysates were determined by adding $50 \mu \mathrm{l}$ of 'substrate solution' from the kit, followed by incubation at $37^{\circ} \mathrm{C}$ for $15 \mathrm{~min}$. The reaction was stopped by the addition of $100 \mu 1$ of 'stopping solution', and the absorbance at $550 \mathrm{~nm}$ was measured with a microplate reader. Cell damage was calculated as a percentage of LDH leakage from damaged cells using the following formula: LDH leakage $(\%)=($ Sup $) /($ Sup + Cell $) \times 100$ where Sup and Cell refer to the absorption of the culture supernatant and cell lysate, respectively.

Annexin V/PI analysis. TACS ${ }^{\mathrm{TM}}$ Annexin V-FITC apoptosis detection kit (Trevigen, Gaithersburg, MD, USA) was used for the detection of early apoptotic and late apoptotic/necrotic cells according to the manufacturer's instructions, Briefly, after treatment with $50 \mu \mathrm{M} \mathrm{Pg}$ for 24 and $48 \mathrm{~h}$, respectively, cells were washed twice with PBS. Then, cells $\left(1 \times 10^{6}\right)$ were resuspended in $100 \mu \mathrm{l}$ Annexin $\mathrm{V}$ incubation reagent $(10 \mathrm{mM}$ HEPES pH 7.4, $150 \mathrm{mM} \mathrm{NaCl}, 5 \mathrm{mM} \mathrm{KCl,} 1 \mathrm{mM} \mathrm{MgCl}_{2}$, 
$1.8 \mathrm{mM} \mathrm{CaCl}_{2}, 5 \mu \mathrm{g} / \mathrm{ml}$ PI, Annexin V-FITC). Cells were incubated in the dark for $15 \mathrm{~min}$ at room temperature, followed by the addition of $400 \mu \mathrm{l}$ binding buffer. Fluorescence intensities of FITC and PI were measured by a FACSCanto flow cytometer. A total of 30, 000 events were acquired, and data were analyzed by Diva software. Annexin V(-)PI(-) cells, Annexin V(+)PI(-) cells and Annexin V(+)PI(+) cells were defined as viable cells, early apoptotic cells and late apoptotic/necrotic cells, respectively.

Western blot analysis. Western blot analysis was carried out according to the methods previously described (24). Briefly, after separation of proteins on a SDS polyacrylamide gel electrophoresis, followed by transferring to a nitrocellulose membrane, protein bands were detected using the following primary antibodies and dilution ratios: rabbit anti-mPR $\alpha$ (BioWorld Technology, Minneapolis, MN, USA) at 1:1,000; rabbit anti-caspase-3 (Enzo Life Sciences, Farmingdale, NY, USA) at 1:1,000; rabbit anticaspase-8 (BD Pharmingen, Franklin Lakes, NJ, USA) at 1:4,000; rabbit anti-caspase-9 (Cell Signaling Technology, Danvers, MA, USA) at 1:1,000; mouse anti-PR (Sigma) at 1:1,000 and $\beta$-actin (Sigma) at 1:5,000. Blotted protein bands were detected with respective horseradish peroxidase-conjugated secondary antibodies and an enhanced chemiluminescence (ECL) Western blot analysis system (GE Healthcare, Buckinghamshire, UK).

Determination of loss of mitochondrial membrane potential $(\Delta \Psi m)$. The $\Delta \Psi \mathrm{m}$ was determined by flow cytometry after cell loading with Rhodamine 123 as previously described with modification (25). Cells were seeded at $1 \times 10^{5}$ cells $/ \mathrm{ml}$, followed by pretreatment with $50 \mathrm{ng} / \mathrm{ml}$ PTX (List Biological Laboratories, Campbell, CA, USA) for $24 \mathrm{~h}$. After washout of PTX, the cell density of PTX-treated and control group cells (non-treated cells) were again adjusted to $1 \times 10^{5}$ cells $/ \mathrm{ml}$, followed by treatment with $50 \mu \mathrm{M}$ Pg for an additional 24-h incubation. After incubation with $10 \mu \mathrm{M}$ Rhodamine 123 in PBS for $15 \mathrm{~min}$ in the dark at room temperature, the fluorescence intensities of Rhodamine 123 were measured by a FACSCanto flow cytometer. A total of 30,000 events were acquired, and data were analyzed by Diva software.

Statistical analysis. Experiments were independently repeated three times, and the results are shown as the means \pm standard deviation (SD) of three assays. The Student's t-test was applied and $\mathrm{P}<0.05$ was considered to indicate a statistically significant result.

\section{Results}

Antiproliferative effect of $\mathrm{Pg}$ on $\mathrm{A} 3$ and 19.2 cell growth. Growth inhibition was observed in both A 3 and I9.2 cells after treatment with $\mathrm{Pg}$ at concentrations ranging from 10 to $100 \mu \mathrm{M}$ for $24 \mathrm{~h}$ and $48 \mathrm{~h}$ in a dose- and time-dependent manner (Fig. 1A and B). The relative growth inhibition rate in the A3 and I9.1 cells was $\sim 50$ and $70 \%$ when treated with $50 \mu \mathrm{M} \mathrm{Pg}$ for 24 and 48 h, respectively (Fig. 1A and B). A similar pattern of growth inhibition was observed in both cell lines regardless of caspase- 8 status (Fig. 1A and B). In contrast, almost no growth
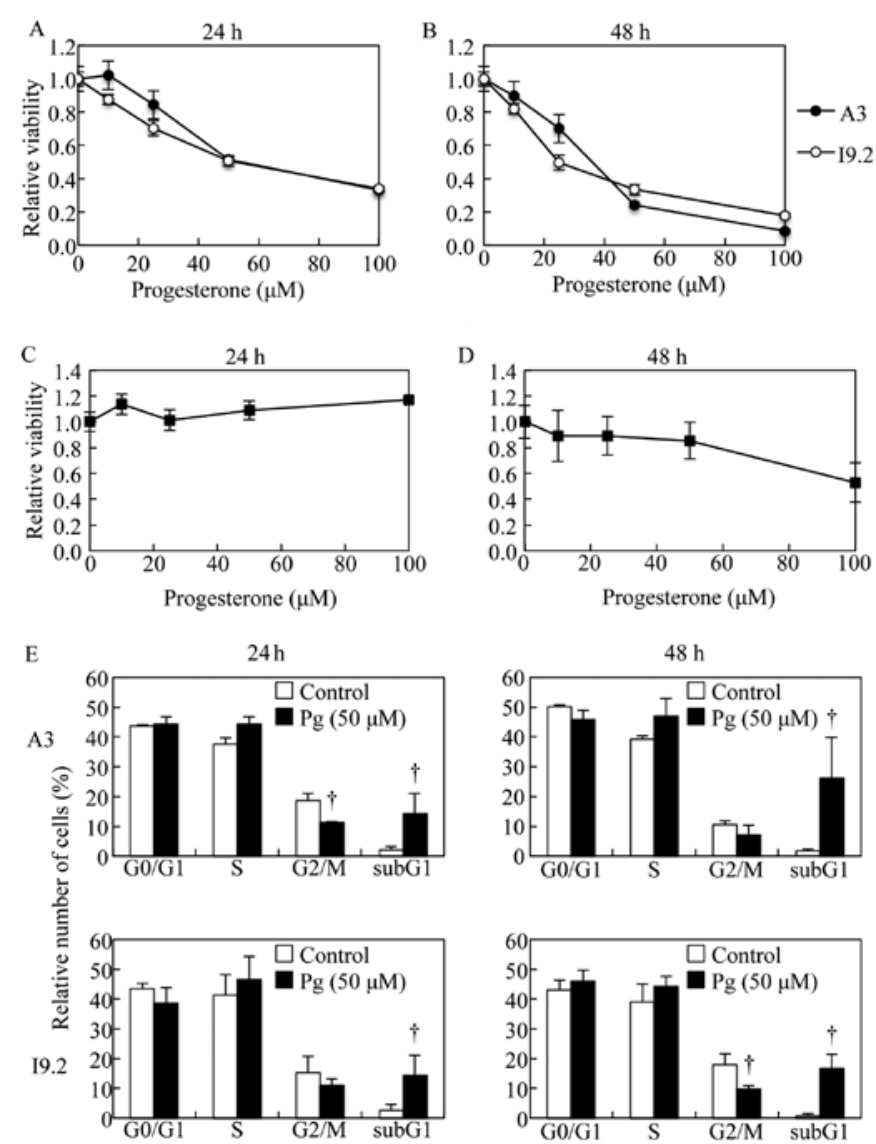

Figure 1. Antiproliferative effects of Pg on A3 and I9.2 cell growth. After treatment with $\mathrm{Pg}$ ranging from 10 to $100 \mu \mathrm{M}$ for 24 and $48 \mathrm{~h}$, cell viability was determined by XTT assay in (A and B) A3 and I9.2 cells, as well as in (C and D) PBMNCs, as described in Materials and methods. (E) After treatment with $50 \mu \mathrm{M}$ Pg for 24 and $48 \mathrm{~h}$, cell cycle analysis was performed using a FACSCanto flow cytometer as described in Materials and methods. Results are shown as the means \pm SD of three separate experiments. Significant differences between control and treatment with Pg are shown $(\mathrm{P}<0.05)$. PBMNCs, peripheral blood mononuclear cells; Pg, progesterone.

inhibition was observed in PBMNCs following treatment with $\mathrm{Pg}$, although a slight but significant growth inhibition was observed in the cells treated with as high as $100 \mu \mathrm{M}$ Pg for $48 \mathrm{~h}$ (Fig. 1C and D). Furthermore, flow cytometric analysis showed that almost no cell cycle arrest was observed in both A 3 and 19.2 cells, although there were trends in a decrease in the number of cells in the G2/M phase in both cell lines after treatment with $50 \mu \mathrm{M}$ Pg for 24 or $48 \mathrm{~h}$ (Fig. 1E). More importantly, a significant increase in the number of cells in sub-G1 phase was observed, indicating apoptosis induction in both A3 and I9.2 cells treated with Pg (Fig. 1E).

$P g$-mediated $L D H$ release and apoptosis induction in $A 3$ and 19.2 cells. The release of $\mathrm{LDH}$ provides an accurate measure of the cell membrane integrity and cell viability. After treatment with $50 \mu \mathrm{M}$ Pg for 48 and $72 \mathrm{~h}$, LDH leakage analysis was thus performed to examine whether Pg treatment affects cell membrane integrity. A time-dependent LDH leakage was observed in both A3 and 19.2 cells irrespective of caspase- 8 deficiency (Fig. 2A). Furthermore, after treatment with $50 \mu \mathrm{M}$ for 24 and $48 \mathrm{~h}$, a significant decrease in the number of viable cells was observed concomitantly with a prominent increase 
A
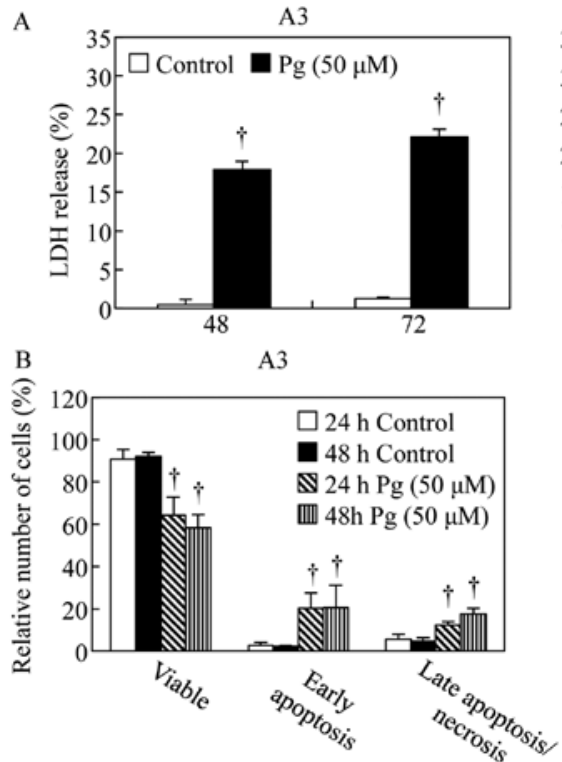

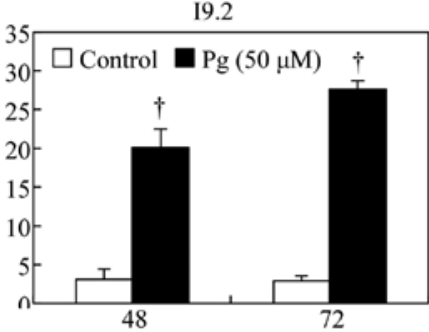

19.2

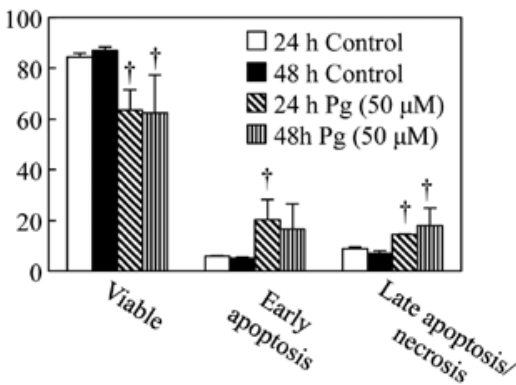

Figure 2. Pg-mediated LDH release and apoptosis induction in A3 and I9.2 cells. (A) After treatment with $50 \mu \mathrm{M}$ Pg for 48 and $72 \mathrm{~h}$, the LDH leakage was measured using the LDH-Cytotoxic test kit as described in Materials and methods. Results are shown as the means \pm SD of three separate experiments. (B) After treatment with $50 \mu \mathrm{M}$ Pg for 24 and $48 \mathrm{~h}$, apoptosis induction was determined by Annexin V/PI staining. Results are shown as the means \pm SD of three separate experiments. Significant differences between control and treatment with Pg are shown ( $\mathrm{P}<0.05)$. Pg, progesterone.
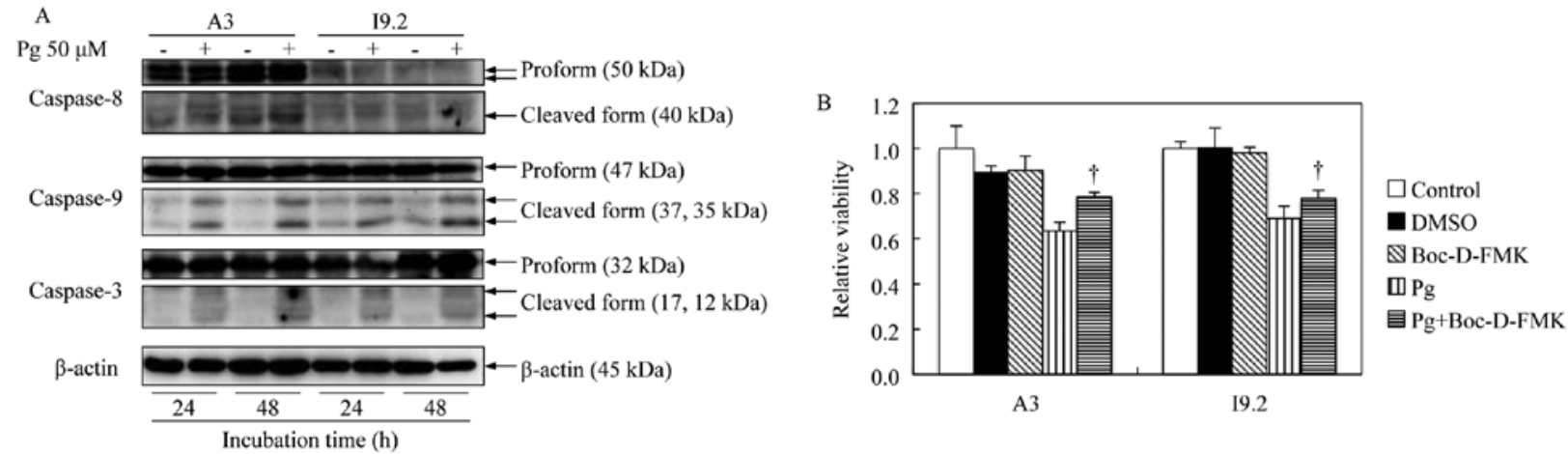

Figure 3. Pg-mediated caspase activation in A3 and I9.2 cells. (A) After treatment with $50 \mu \mathrm{M}$ of Pg for 24 and $48 \mathrm{~h}$, western blot analysis was carried out to detect the activation of caspase- $8,-9$ and -3 . (B) After treatment with $50 \mu \mathrm{M}$ of Pg in the presence or absence of $25 \mu \mathrm{M}$ Boc-D-FMK for $24 \mathrm{~h}$, cell viability was determined by XTT assay. Relative cell viability was calculated by the same manner as described in the legend of Fig. 1. Results are shown as the means \pm SD of three separate experiments. Significant differences between Pg treatment and Pg+Boc-D-FMK treatment are shown ( $\mathrm{P}<0.05$ ). $\mathrm{Pg}$, progesterone.

in the number of apoptotic cells in both the A3 and 19.2 cell lines (Fig. 2B).

Pg-mediated caspase activation in A3 and 19.2 cells. After treatment with $50 \mu \mathrm{M}$ Pg for 24 and $48 \mathrm{~h}$, western blot analysis was conducted to determine the activation of caspase-8, -9 and -3 . As expected, neither the proform nor the cleaved form of caspase- 8 was observed in caspase-8-deficient I9.2 cells, whereas its cleaved form was observed in A3 cells after Pg treatment, indicating the activation of caspase- 8 in these cells (Fig. 3A). Furthermore, an increased amount of the cleaved form of caspase- 9 and caspase- 3 was observed in both A3 and I9.2 cells (Fig. 3A). These results clearly indicate that caspase cascade activation is responsible for Pg-mediated apoptosis induction. Moreover, the addition of a pan-caspase inhibitor, Boc-D-FMK, significantly suppressed Pg-triggered cytocidal effects in both cells, reconfirming the involvement of caspase cascade activation (Fig. 3B).
Contribution of $m P R \alpha$ to Pg-induced loss of mitochondrial membrane potential $\left(\Delta \Psi_{m}\right)$ in A3 and I9.2 cells. Western blot analysis was performed to identify the presence of $\mathrm{mPR} \alpha$. In both cell types, the expression of mPR $\alpha$ was observed, and its expression level was not affected by the administration of $50 \mu \mathrm{M} \mathrm{Pg}$ for 24 and $48 \mathrm{~h}$ (Fig. 4A). Furthermore, the expression of classic PR (PR-A and PR-B) was not detected in both cell lines (data not shown), as has been previously reported $(17,18)$.

After treatment with $50 \mu \mathrm{M}$ Pg for $24 \mathrm{~h}$, Rhodamine 123, a cell-permeant cationic fluorescent dye, was used to assay $\Delta \Psi \mathrm{m}$ in both $\mathrm{A} 3$ and $\mathrm{I} 9.2$ cells. The administration of $\mathrm{Pg}$ resulted in a significant increase in cell populations with decreased $\Delta \Psi \mathrm{m}$ (decrease in fluorescence intensity) (Fig. 4B). However, the cell populations with decreased $\Delta \Psi$ m were notably restored by pretreatment with PTX, an inhibitor specific for $\mathrm{Gi}$ protein directly coupled to $\mathrm{mPR} \alpha$ (Fig. 4B). 


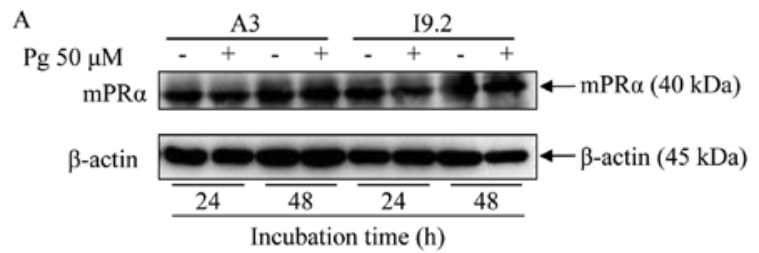

B
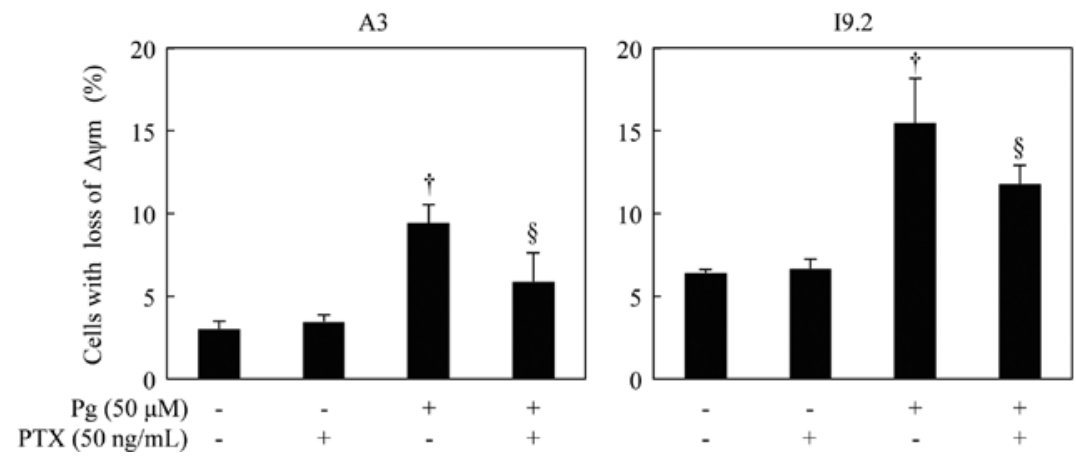

Figure 4. Contribution of mPR $\alpha$ to Pg-induced loss of $\Delta \Psi \mathrm{m}$ in A3 and I9.2 cells. (A) After treatment with $50 \mu \mathrm{M}$ of Pg for 24 and $48 \mathrm{~h}$, western blot analysis was carried out to detect the expression of $\mathrm{mPR} \alpha$. (B) Both cell lines were preincubated with or without PTX ( $50 \mathrm{ng} / \mathrm{ml}$ ) for $24 \mathrm{~h}$, followed by treatment with $50 \mu \mathrm{M}$ $\mathrm{Pg}$ for an additional 24-h incubation. The loss of $\Delta \Psi \mathrm{m}$ was determined using Rhodamine 123 by FACS analysis. Results are shown as the means \pm SD of three separate experiments. A P-value $<0.05$ was considered to indicate a statistically significant result ( ${ }^{\mathrm{P}} \mathrm{P}<0.05 \mathrm{vs}$. control; ${ }^{\circledR} \mathrm{P}<0.05$ vs. Pg alone). Pg, progesterone.

\section{Discussion}

In the present study, we demonstrated that $\mathrm{Pg}$-mediated growth suppression was observed in both A3 and I9.2 cells in a dose- and time-dependent manner. Notably, no significant difference in the degree of growth suppression between A3 and 19.2 (caspase-8-deficient) cells was observed, suggesting that the growth suppression was caspase- 8 independent. As expected, much less cytotoxicity was observed in PBMNCs when treated with concentrations of Pg, which showed significant cytotoxicity in both cell lines. These results reconfirmed a high tolerance of $\mathrm{Pg}$ for clinical application.

It has been demonstrated that G0/G1 cell cycle arrest and apoptosis induction contributed to Pg-mediated growth inhibition in C-4I cells, a cervical cell line lacking classic PR (8). However, almost no arrest at a particular cell cycle phase was observed, despite there were trends in a decrease in the number of $\mathrm{G} 2 / \mathrm{M}$ phase cells in both the A3 and 19.2 cells. This discrepancy between C-4I and A3 as well as I9.2 cells might be due to a cell type-specific event. Notably, a significant accumulation of cells in the sub-G1 phase was observed after treatment with $\mathrm{Pg}$, suggesting that Pg-mediated growth suppression is attributed to apoptosis induction rather than cell cycle arrest. Furthermore, apoptosis induction as evidenced by Annexin $\mathrm{V}$ analysis strengthened our hypothesis. Apart from apoptosis induction, secondary necrosis probably also contributed to Pg-mediated growth inhibition in both cells types since the disruption of membrane integrity after treatment with Pg for 48 and $72 \mathrm{~h}$ was clearly demonstrated by the release of LDH.

In order to clarify the molecular details of the apoptosis pathway, we focused on the activation of caspases including caspase- $9,-8$ and -3 , which are key players in two principal signaling pathways of apoptosis induction, called the intrinsic and extrinsic pathway $(26,27)$. The intrinsic mechanism of apoptosis involves a disruption of the mitochondrial cell membrane, resulting in the loss of $\Delta \Psi \mathrm{m}$ associated with cytochrome $c$ release, followed by the activation of capase- 9 and caspase-3 (26-28). In contrast, the extrinsic pathway induced by death receptors, such as Fas and tumor necrosis factor receptor, is responsible for the activation of caspase- 8 accompanied by the activation of caspase-3 $(27,28)$. In the present study, we demonstrated that the activation of capase- $9,-8$ and -3 was observed in A3 cells after Pg treatment, suggesting that not only the intrinsic pathway but also the extrinsic pathway was involved in Pg-mediated apoptosis induction in the cells. To the best of our knowledge, this is the first report showing the involvement of the intrinsic pathway in Pg-mediated apoptosis in A3 cells, although Fas-mediated apoptosis induction through caspase- 8 has been well documented in these cells $(17,18)$. Therefore, an experiment focused on the activation of Bid, a pro-apoptotic Bcl-2 family protein and responsible for the crosstalk between intrinsic and extrinsic pathway $(29,30)$, is needed to clarify the relationship between the two principal pathways. Furthermore, the activation of caspase- 9 and -3 was observed in caspase-8-deficient 19.2 cells, suggesting that the intrinsic pathway, instead of the extrinsic pathway, is involved in Pg-mediated apoptosis induction in the cells. Collectively, these results suggest that the activation of the caspase cascade associated with the intrinsic and/or extrinsic pathway is responsible for Pg-mediated apoptosis in A3 as well as in 19.2 cells. In fact, suppression of apoptosis by the addition of a pan-caspase inhibitor, Boc-D-FMK, also supported our hypothesis. We also demonstrated that exposure to Pg induced loss of $\Delta \Psi \mathrm{m}$ in both cells, which strongly supports our hypothesis of the involvement of the intrinsic pathway.

Since the lack of classic PR has been demonstrated in Jurkat cells $(16,31)$, in order to clarify the molecular mechanisms of Pg action, the involvement of mPR $\alpha$ was investigated, a molecular of which the function and regulation 
has been best characterized among the mPRs $(19,20,32)$. In the present study, the expression of $\mathrm{mPR} \alpha$ was observed, and its expression level was not affected by the administration of Pg. Importantly, pretreatment with PTX, an inhibitor specific for Gi protein activation $(13,16,33)$, significantly restored the decreased $\Delta \Psi \mathrm{m}$ resulting from exposure to Pg. Collectively, these results suggest that $\mathrm{mPR} \alpha$ contributes to Pg-mediated apoptosis induction in Jurkat cells devoid of classic PR.

In conclusion, growth suppression accompanied by apoptosis induction of Jurkat cells devoid of classic PR by Pg, was mediated through mitochondrial membrane disruption followed by the activation of the caspase cascade, as a result of the activation of non-genomic effects. Results of the present study offer a novel concept of $\mathrm{Pg}$ actions towards its clinical application for patients with lymphocytic $\mathrm{T}$ cell leukemia. Furthermore, the present study provides novel insight into the function of $\mathrm{Pg}$ as a regulator of the immune response.

\section{Acknowledgements}

The present study was supported, in part, by grants from the Ministry of Education, Culture, Sports, Science and Technology and by the Promotion and the Mutual Aid Corporation for Private Schools of Japan.

\section{References}

1. Conneely OM, Mulac-Jericevic B, DeMayo F, Lydon JP and O'Malley BW: Reproductive functions of progesterone receptors. Recent Prog Horm Res 57: 339-355, 2002.

2. Hughes GC: Progesterone and autoimmune disease. Autoimmun Rev 11: A502-A514, 2012.

3. Matsuzaki J, Tsuji T, Imazeki I, Ikeda $\mathrm{H}$ and Nishimura T: Immunosteroid as a regulator for Th1/Th2 balance: its possible role in autoimmune diseases. Autoimmunity 38: 369-375, 2005.

4. Ahmad N and Kumar R: Steroid hormone receptors in cancer development: a target for cancer therapeutics. Cancer Lett 300: $1-9,2011$.

5. Hellberg D: Sex steroids and cervical cancer. Anticancer Res 32: 3045-3054, 2012.

6. Horita K, Inase N, Miyake S, Formby B, Toyoda H and Yoshizawa Y: Progesterone induces apoptosis in malignant mesothelioma cells. Anticancer Res 21: 3871-3874, 2001.

7. Lanari C, Wargon V, Rojas P and Molinolo AA: Antiprogestins in breast cancer treatment: are we ready? Endocr Relat Cancer 19: R35-R50, 2012.

8. Bertelsen EL, Endresen PC, Orbo A and Sager G: Non-genomic cell growth inhibition by progesterone. cell cycle retardation and induction of cell death. Anticancer Res 24: 3749-3755, 2004.

9. Falkenstein E, Tillmann HC, Christ M, Feuring $M$ and Wehling M: Multiple actions of steroid hormones - a focus on rapid, nongenomic effects. Pharmacol Rev 52: 513-556, 2000.

10. Zhu Y, Hanna RN, Schaaf MJ, Spaink HP and Thomas P Candidates for membrane progestin receptors - past approaches and future challenges. Comp Biochem Physiol C Toxicol Pharmacol 148: 381-389, 2008

11. Hammes SR and Levin ER: Minireview: recent advances in extranuclear steroid receptor actions. Endocrinology 152: 4489-4495, 2011.

12. Ndiaye K, Poole DH, Walusimbi S, Cannon MJ, Toyokawa K, Maalouf SW, Dong J, Thomas P and Pate JL: Progesterone effects on lymphocytes may be mediated by membrane progesterone receptors. J Reprod Immunol 95: 15-26, 2012.

13. Dressing GE, Goldberg JE, Charles NJ, Schwertfeger KL and Lange CA: Membrane progesterone receptor expression in mammalian tissues: a review of regulation and physiological implications. Steroids 76: 11-17, 2011.

14. Thomas P: Characteristics of membrane progestin receptor alpha $(\mathrm{mPR} \alpha)$ and progesterone membrane receptor component 1 (PGMRC1) and their roles in mediating rapid progestin actions. Front Neuroendocrinol 29: 292-312, 2008.
15. Gamberucci A, Giunti R and Benedetti A: Progesterone inhibits capacitative $\mathrm{Ca}^{2+}$ entry in Jurkat $\mathrm{T}$ lymphocytes by a membrane delimited mechanism, independently of plasma membrane depolarization. Cell Calcium 36: 175-180, 2004.

16. Dosiou C, Hamilton AE, Pang Y, Overgaard MT, Tulac S, Dong J, Thomas P and Giudice LC: Expression of membrane progesterone receptors on human T lymphocytes and Jurkat cells and activation of G-proteins by progesterone. J Endocrinol 196: 67-77, 2008.

17. Juo P, Kuo CJ, Yuan J and Blenis J: Essential requirement for caspase-8/FLICE in the initiation of the Fas-induced apoptotic cascade. Curr Biol 8: 1001-1008, 1998.

18. Juo P, Woo MS, Kuo CJ, Signorelli P, Biemann HP, Hannun YA and Blenis J: FADD is required for multiple signaling events downstream of the receptor Fas. Cell Growth Differ 10: 797-804, 1999.

19. Thomas P, Tubbs C, Detweiler C, Das S, Ford L and Breckenridge-Miller D: Binding characteristics, hormonal regulation and identity of the sperm membrane progestin receptor in Atlantic croaker. Steroids 70: 427-433, 2005.

20. Zhu Y, Rice CD, Pang Y, Pace M and Thomas P: Cloning, expression, and characterization of a membrane progestin receptor and evidence it is an intermediary in meiotic maturation of fish oocytes. Proc Natl Acad Sci USA 100: 2231-2236, 2003.

21. Imai M, Kikuchi H, Denda T, Ohyama K, Hirobe $C$ and Toyoda H: Cytotoxic effects of flavonoids against a human colon cancer derived cell line, COLO 201: a potential natural anticancer substance. Cancer Lett 276: 74-80, 2009.

22. Darzynkiewicz Z, Bruno S, Del Bino G, Gorczyca W, Hotz MA, Lassota P and Traganos F: Features of apoptotic cells measured by flow cytometry. Cytometry 13: 795-808, 1992.

23. Yoshino Y, Yuan B, Kaise T, Takeichi M, Tanaka S, Hirano T, Kroetz DL and Toyoda H: Contribution of aquaporin 9 and multidrug resistance-associated protein 2 to differential sensitivity to arsenite between primary cultured chorion and amnion cells prepared from human fetal membranes. Toxicol Appl Pharmacol 257: 198-208, 2011.

24. Yuan B, Ohyama K, Bessho T and Toyoda H: Contribution of inducible nitric oxide synthase and cyclooxygenase- 2 to apoptosis induction in smooth chorion trophoblast cells of human fetal membrane tissues. Biochem Biophys Res Commun 341: 822-827, 2006.

25. Johnson LV, Walsh ML and Chen LB: Localization of mitochondria in living cells with rhodamine 123. Proc Natl Acad Sci USA 77: 990-994, 1980.

26. Ryter SW, Kim HP, Hoetzel A, Park JW, Nakahira K, Wang X and Choi AM: Mechanisms of cell death in oxidative stress. Antioxid Redox Signal 9: 49-89, 2007.

27. Yuan B, Yoshino Y, Kaise T and Toyoda H: Application of arsenic trioxide therapy for patients with leukaemia. In: Biological Chemistry of As, Sb and Bi. Sun HZ (ed). John Wiley \& Sons, Ltd., New York, pp263-292, 2011.

28. Earnshaw WC, Martins LM and Kaufmann SH: Mammalian caspases: structure, activation, substrates, and functions during apoptosis. Annu Rev Biochem 68: 383-424, 1999.

29. Kantari C and Walczak H: Caspase- 8 and bid: caught in the act between death receptors and mitochondria. Biochim Biophys Acta 1813: 558-563, 2011.

30. Viswanath V, Wu Y, Boonplueang R, Chen S, Stevenson FF, Yantiri F, Yang L, Beal MF and Andersen JK: Caspase-9 activation results in downstream caspase- 8 activation and bid cleavage in 1-methyl-4-phenyl-1,2,3,6-tetrahydropyridine-induced Parkinson's disease. J Neurosci 21: 9519-9528, 2001.

31. Bamberger CM, Else T, Bamberger AM, Beil FU and Schulte HM: Dissociative glucocorticoid activity of medroxyprogesterone acetate in normal human lymphocytes. J Clin Endocrinol Metab 84: 4055-4061, 1999.

32. Xie M, Zhu X, Liu Z, Shrubsole M, Varma V, Mayer IA, Dai Q, Chen Q and You S: Membrane progesterone receptor alpha as a potential prognostic biomarker for breast cancer survival: a retrospective study. PloS One 7: e35198, 2012.

33. Karteris E, Zervou S, Pang Y, Dong J, Hillhouse EW, Randeva HS and Thomas P: Progesterone signaling in human myometrium through two novel membrane $\mathrm{G}$ protein-coupled receptors: potential role in functional progesterone withdrawal at term. Mol Endocrinol 20: 1519-1534, 2006. 